This item was submitted to Loughborough's Research Repository by the author.

Items in Figshare are protected by copyright, with all rights reserved, unless otherwise indicated.

\title{
Generalized extended state observer based control for systems with mismatched uncertainties
}

PLEASE CITE THE PUBLISHED VERSION

http://ieeexplore.ieee.org/xpls/abs_all.jsp?arnumber=6117083

PUBLISHER

(C) IEEE

VERSION

AM (Accepted Manuscript)

LICENCE

CC BY-NC-ND 4.0

\section{REPOSITORY RECORD}

Li, Shihua, Jun Yang, Wen-Hua Chen, and Xisong Chen. 2012. "Generalized Extended State Observer Based Control for Systems with Mismatched Uncertainties”. figshare. https://hdl.handle.net/2134/11121. 
This item was submitted to Loughborough's Institutional Repository (https://dspace.lboro.ac.uk/) by the author and is made available under the following Creative Commons Licence conditions.

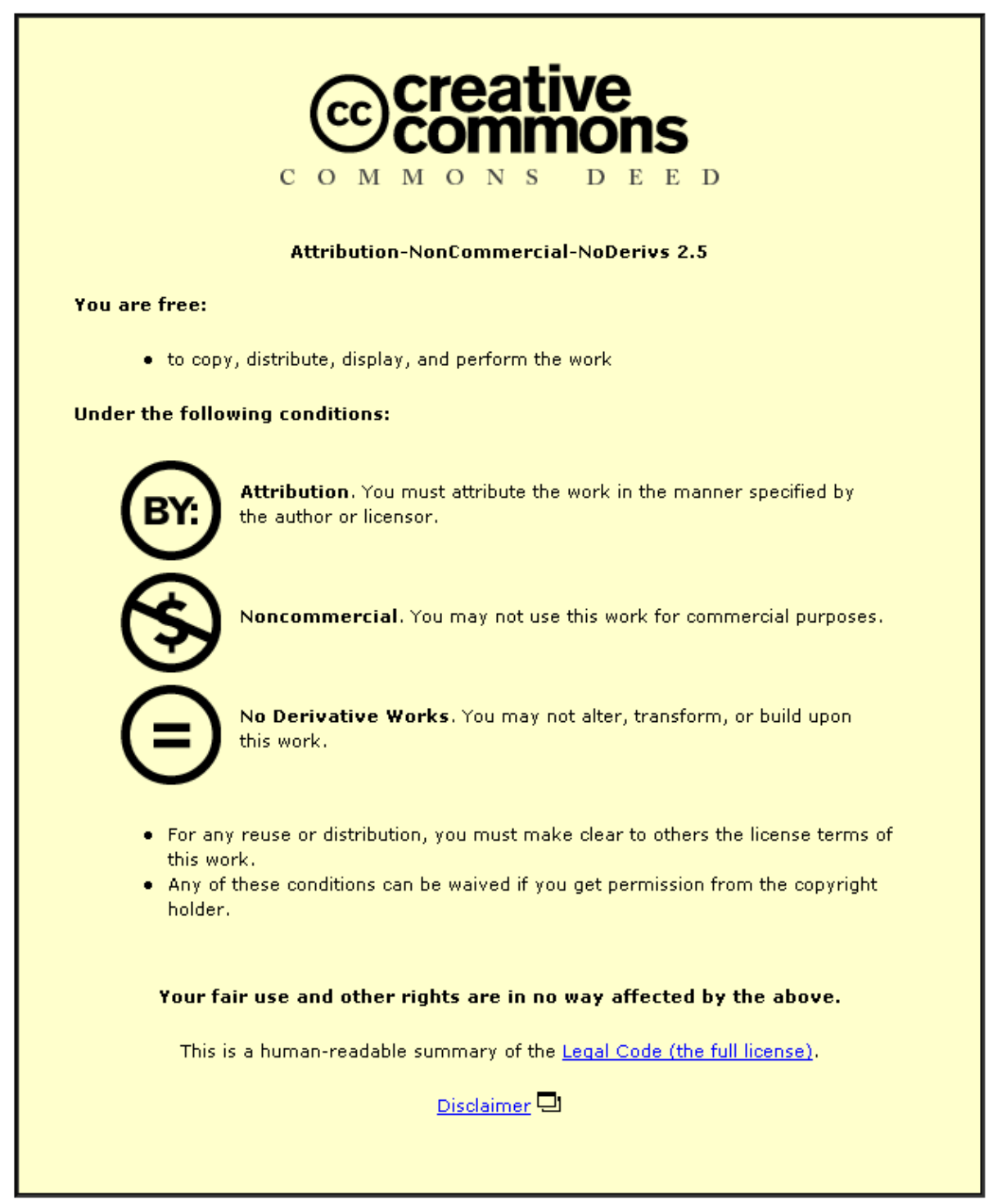

For the full text of this licence, please go to: http://creativecommons.org/licenses/by-nc-nd/2.5/ 


\section{Generalized Extended State Observer Based Control for Systems with Mismatched Uncertainties}

\begin{abstract}
The standard extended state observer based control (ESOBC) method is only applicable for a class of single-inputsingle-output (SISO) integral chain systems with matched uncertainties. It is noticed that systems with non-integral-chain form and mismatched uncertainties are more general and widely exist in practical engineering systems, where the standard ESOBC method is no longer available. To this end, it is imperative to explore new ESOBC approach for these systems to extend its applicability. By appropriately choosing a disturbance compensation gain, a generalized extended state observer based control (GESOBC) method is proposed for non-integral-chain systems subject to mismatched uncertainties without any coordinate transformations. The proposed method is able to extend to multiinput-multi-output (MIMO) systems with almost no modification. Both numerical and application design examples demonstrate the feasibility and efficacy of the proposed method.
\end{abstract}

Index Terms-Generalized extended state observer based control, mismatched uncertainties, MIMO system, non-integralchain system, disturbance rejection, disturbance compensation gain.

\section{INTRODUCTION}

$\mathbf{V}$ ARIOUS uncertainties including unmodeled dynamics, parameter perturbations, and external disturbances, always bring adverse effects on modern industrial control systems. With the growing interest in high-precision control, the utilization of the disturbance rejection technique is generally required in the controller design. It is well-known that feedforward compensation control, which requires the measurement of the disturbance, is one of the most effective disturbance rejection method. One fact should be pointed out is that many uncertainties in control systems are unmeasurable, thus the disturbance estimation technique is particularly crucial for disturbance attenuation.

During the past decades, several elegant approaches have been proposed to estimate disturbances, including the unknown input observer (UIO) [1], the disturbance observer (DOB) [2]-[6], the perturbation observer (POB) [7], [8], the equivalent input disturbance (EID) based estimation [9], [10], and the extended state observer (ESO) [11]-[15], Note that all these methods are designed based on the model of the plant. A natural doubt may be what does a designer have to know about the plant in order to build the estimator [12]. Among the above listed approaches, ESO requires the least amount of plant information [16], in fact, only the system order should be known. Due to such a promising feature, ESO based control (ESOBC) schemes, also known as active disturbance rejection control (ADRC), have become more and more popular in recent years. Successful applications of ESOBC in various industrial systems, including robotic systems [17], [18], motion control systems [19]-[24], manipulator systems [25], [26], power converter [27], [28], gyroscopes [29], and flight control systems [30]-[32], have been reported within the past decade.

Although the ESOBC has obtained successful achievements in many practical control systems, it is also noticed that ESOBC mainly has its roots in motion control systems. The potential reason is that the standard ESOBC are only available for integral chain systems which widely exist in motion control systems. Such integral chain form is not necessarily satisfied for general systems, and it is required to transfer the system to meet the standard formulation by coordinate transformations such that the standard ESOBC method can be used. However, as pointed out by Han [14], it is generally not easy to reformulate the problem to satisfy the standard formulation, which becomes one of the most crucial factor restricting the applicability of the ESOBC.

Another factor that severely constrains the application of standard ESOBC method is the uncertainties in many practical systems may not satisfy the so called matching condition [33] which implies that the uncertainties act via the same channel as the control input. For example, in flight control systems, the lumped disturbance torques caused by unmodeled dynamics, external winds, and parameter perturbations, etc., always affects the states directly rather than through the input channels [34]. Another example in the MAGLEV suspension system is that the track input disturbance acts on different channel from the control input [40]. The problem also appears in a permanent magnet synchronous motor system, in which the uncertainties consisting of the parameter variation and the load torque enter system via different channels from the control inputs [35].

Note that disturbance based feedforward control for systems with mismatched uncertainties is a longstanding unresolved problem [41], [42]. A generalized extended state observer based control (GESOBC) method is proposed in this paper to solve the disturbance attenuation problem of a class of non-integral-chain system with mismatched uncertainties. It is shown that by properly choosing a disturbance compensation gain, the mismatched uncertainties can be attenuated from the system output. A systematic method is developed for the disturbance compensation gain design. Parameter selection of the proposed method is discussed in detail. In addition, feasible conditions for extending the proposed GESOBC to multiinput-multi-output (MIMO) systems without any coordinate transformations are also investigated. The proposed GESOBC method largely extends the applicability of the ESOBC since it exhibits many superiorities over the standard ESBOC method, which are listed in Table I where the essential-integral-chain systems refers to the systems that can be converted into integral chain systems by transformation.

The remainder of the paper is organized as follows. In 
TABLE I

APPLICABILITY OF THE PROPOSED GESOBC AND THE ESOBC

\begin{tabular}{|c|c|c|c|}
\hline Method & Disturbance type & Variable type & System type \\
\hline GESOBC & mismatched/matched & MIMO & non-integral-chain \\
\hline ESOBC & matched & SISO & essential-integral-chain \\
\hline
\end{tabular}

Section II, preliminary results regarding the formulation of the standard ESOBC are presented. Section III investigates the newly proposed GESOBC for general systems with mismatched uncertainties. In Section IV, some related problems about the proposed method are further discussed. Application example and simulations are studied to demonstrate the efficiency of the proposed method in Section V. Finally, the concluding remarks are summarized in Section VI.

\section{PReliminary-STANDARD ESOBC}

An uncertain system with the order of $n$ under the standard consideration is usually a integral chain system, described by [11]

$$
\left\{\begin{aligned}
\dot{x}_{1} & =x_{2}, \\
\dot{x}_{2} & =x_{3}, \\
& \vdots \\
\dot{x}_{n} & =f\left(x_{1}, \cdots, x_{n}, \omega(t), t\right)+b u . \\
y & =x_{1} .
\end{aligned}\right.
$$

where $x_{1}, \cdots, x_{n}$ are the states, $u$ is the control input, $y$ is the output, $\omega(t)$ is the external disturbance, $b$ is the system parameter, and $f\left(x_{1}, \cdots, x_{n}, \omega(t), t\right)$ represent the uncertain function, also known as lumped disturbance.

In the framework of ESOBC, an augmented variable[13]

$$
x_{n+1}=f\left(x_{1}, \cdots, x_{n}, \omega(t), t\right),
$$

is introduced to linearize system (1). Combining (1) with (2), the extended state equation is given by

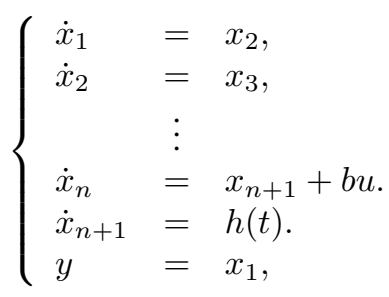

with $h(t)=\dot{f}\left(x_{1}, \cdots, x_{n}, \omega(t), t\right)$

In order to estimate the states, a linear ESO is designed as [11]

$$
\left\{\begin{array}{l}
\dot{z}_{1}=z_{2}-\beta_{1}\left(z_{1}-y\right), \\
\dot{z}_{2}=z_{3}-\beta_{2}\left(z_{1}-y\right), \\
\quad \vdots \\
\dot{z}_{n}=z_{n+1}-\beta_{n}\left(z_{1}-y\right)+b u \\
\dot{z}_{n+1}=-\beta_{n+1}\left(z_{1}-y\right),
\end{array}\right.
$$

where $z_{1}, z_{2}, \cdots, z_{n}$, and $z_{n+1}$ are estimates of states $x_{1}, x_{2}, \cdots, x_{n}$, and $x_{n+1}$, respectively, $\beta_{1}, \beta_{2}, \cdots, \beta_{n+1}$ are the observer gains.
Subtracting (3) from (4), the error system is written as

$$
\left\{\begin{array}{l}
\dot{e}_{1}=e_{2}-\beta_{1} e_{1}, \\
\dot{e}_{2}=e_{3}-\beta_{2} e_{1}, \\
\vdots \\
\dot{e}_{n}=e_{n+1}-\beta_{n} e_{1}, \\
\dot{e}_{n+1}=-\beta_{n+1} e_{1}-h(t),
\end{array}\right.
$$

where $e_{i}=z_{i}-x_{i}(i=1,2, \cdots, n+1)$ represents estimation error. By properly choosing the observer gains $\beta_{1}, \beta_{2}, \cdots, \beta_{n+1}$, the bounded stability of (5) is guaranteed under the assumption that $h(t)$ is bounded [26].

The standard ESOBC control law is usually designed as [13], [14]

$$
u=\boldsymbol{K}_{x} \boldsymbol{x}-\frac{z_{n+1}}{b},
$$

where $\boldsymbol{K}_{x}$ is the feedback control gain.

\section{Generalized EXTEnded StATE ObSERVER BASED CONTROL}

\section{A. Problem Statement}

The standard ESOBC method is possibly not available for the following simple second-order system

$$
\left\{\begin{array}{l}
\dot{x}_{1}=x_{1}-2 x_{2}+f\left(x_{1}, x_{2}, \omega(t), t\right), \\
\dot{x}_{2}=x_{1}+x_{2}+u .
\end{array}\right.
$$

System (7) does not satisfy the standard formulation as (1) in the following two aspects. On the one hand, (7) does not satisfy the integral chain form. On the other hand, the uncertainties $f\left(x_{1}, x_{2}, \omega(t), t\right)$ enter the system with a different channel from the control input $u$, i.e., the so called matching condition is not satisfied. For the above mentioned case, the standard ESOBC law (6) is no longer available. Thus it is imperative to develop generalized extended state observe based control (GESOBC) for general systems which do not satisfy the standard formulation of system (1).

For the sake of simplicity, the following single-input-singleoutput (SISO) system with mismatched uncertainties is considered

$$
\left\{\begin{array}{l}
\dot{\boldsymbol{x}}=\boldsymbol{A} \boldsymbol{x}+\boldsymbol{b}_{u} u+\boldsymbol{b}_{d} f(\boldsymbol{x}, \omega(t), t) \\
\boldsymbol{y}_{m}=\boldsymbol{C}_{m} \boldsymbol{x} \\
y_{o}=\boldsymbol{c}_{o} \boldsymbol{x}
\end{array}\right.
$$

where $\boldsymbol{x} \in \boldsymbol{R}^{n}, u \in \boldsymbol{R}, \omega \in \boldsymbol{R}, \boldsymbol{y}_{m} \in \boldsymbol{R}^{r}$, and $y_{o} \in \boldsymbol{R}$ are the state vector, input, external disturbance, measurable outputs and controlled output, respectively. $f(\boldsymbol{x}, \omega(t), t)$ is the uncertain function in terms of $\boldsymbol{x}$ and $\omega$. $\boldsymbol{A}$ with dimension $n \times n, \boldsymbol{b}_{u}$ with dimension $n \times 1, \boldsymbol{b}_{d}$ with dimension $n \times 1$, $C_{m}$ with dimension $r \times n$, and $c_{o}$ with dimension $1 \times n$ are system matrices, respectively.

Remark 1: In (8), uncertainty function $f(\boldsymbol{x}, \omega(t), t)$ represents the lumped disturbance, which is a generalized concept, possibly including external disturbances, unmodeled dynamics, parameter variations, and complex nonlinear dynamics which may be difficult for the feedback part to handle.

Remark 2: Eq. (8) represents a more general class of systems as compared with that of system (1) since system (8) is not confined to integral chain form and may subject to mismatched uncertainties [37]. The matching case is a special case of (8), by simply taking $\boldsymbol{b}_{u}=\lambda \boldsymbol{b}_{d}, \lambda \in \boldsymbol{R}$. 


\section{B. Composite Control Design}

Similar to the standard case in Section II, adding an extended variable

$$
x_{n+1}=d=f(\boldsymbol{x}, \omega(t), t),
$$

to linearize system (8), the extended system equation is obtained

$$
\left\{\begin{array}{l}
\dot{\overline{\boldsymbol{x}}}=\overline{\boldsymbol{A}} \overline{\boldsymbol{x}}+\overline{\boldsymbol{b}}_{u} u+\boldsymbol{E} h(t) \\
\boldsymbol{y}_{m}=\overline{\boldsymbol{C}}_{m} \overline{\boldsymbol{x}}
\end{array}\right.
$$

where variables

$$
\begin{aligned}
\overline{\boldsymbol{x}} & =\left[\begin{array}{c}
\boldsymbol{x} \\
x_{n+1}
\end{array}\right], \\
h(t) & =\frac{d f(\boldsymbol{x}, \omega(t), t)}{d t},
\end{aligned}
$$

and matrices

$$
\begin{gathered}
\overline{\boldsymbol{A}}=\left[\begin{array}{cc}
\boldsymbol{A}_{n \times n} & \left(\boldsymbol{b}_{d}\right)_{n \times 1} \\
\mathbf{0}_{1 \times n} & 0_{1 \times 1}
\end{array}\right]_{(n+1) \times(n+1)}, \\
\overline{\boldsymbol{b}}_{u}=\left[\begin{array}{c}
\left(\boldsymbol{b}_{u}\right)_{n \times 1} \\
0_{1 \times 1}
\end{array}\right]_{(n+1) \times 1}, \\
\boldsymbol{E}=\left[\begin{array}{c}
\mathbf{0}_{n \times 1} \\
1_{1 \times 1}
\end{array}\right]_{(n+1) \times 1}, \\
\overline{\boldsymbol{C}}_{m}=\left[\boldsymbol{C}_{m}, 0_{r \times 1}\right]_{r \times(n+1)} .
\end{gathered}
$$

Assumption 1: $\left(\boldsymbol{A}, \boldsymbol{b}_{u}\right)$ is controllable, and $\left(\overline{\boldsymbol{A}}, \overline{\boldsymbol{C}}_{m}\right)$ is observable.

Remark 3: A necessary condition of $\left(\bar{A}, \bar{C}_{m}\right)$ observable is that $\left(\boldsymbol{A}, \boldsymbol{C}_{m}\right)$ observable. The details can be found in Appendix A.

For system (10), the extended state observer is designed as follows

$$
\left\{\begin{array}{l}
\dot{\hat{\bar{x}}}=\overline{\boldsymbol{A}} \hat{\overline{\boldsymbol{x}}}+\overline{\boldsymbol{b}}_{u} u+\boldsymbol{L}\left(\boldsymbol{y}_{m}-\hat{\boldsymbol{y}}_{m}\right) \\
\hat{\boldsymbol{y}}_{m}=\overline{\boldsymbol{C}}_{m} \hat{\overline{\boldsymbol{x}}}
\end{array}\right.
$$

where $\hat{\overline{\boldsymbol{x}}}=\left[\hat{\boldsymbol{x}}^{T}, \hat{x}_{n+1}\right]^{T}, \hat{\boldsymbol{x}}$, and $\hat{x}_{n+1}$ are the estimates of the state variable $\bar{x}, x$, and $x_{n+1}$ in (10), respectively. Matrix $\boldsymbol{L}$ with dimension $(n+1) \times r$ is the observer gain to be designed.

In the presence of mismatched uncertainties, the standard ESOBC law, $u=\boldsymbol{K}_{x} \boldsymbol{x}-\hat{d}$ (where $\hat{d}=\hat{x}_{n+1}, \boldsymbol{K}_{x}$ the feedback control gain), can not effectively compensate the uncertainties in system (8).

Remark 4: It should be pointed out that the mismatched uncertainties can not be attenuated completely from the state equation no matter what controller is designed [43]. In this case, one of the most achievable goal is to remove the uncertainties from the output channel in steady state.

The $\overline{\bar{\equiv}}$ osite control law in this paper is designed as

$$
u=\boldsymbol{K}_{x} \boldsymbol{x}+K_{d} \hat{d},
$$

or

$$
u=\boldsymbol{K}_{x} \hat{\boldsymbol{x}}+K_{d} \hat{d},
$$

where $\boldsymbol{K}_{x}$ is the feedback control gain, and $K_{d}$ is the disturbance compensation gain, designed as

$$
K_{d}=-\left[\boldsymbol{c}_{o}\left(\boldsymbol{A}+\boldsymbol{b}_{u} \boldsymbol{K}_{x}\right)^{-1} \boldsymbol{b}_{u}\right]^{-1} \boldsymbol{c}_{o}\left(\boldsymbol{A}+\boldsymbol{b}_{u} \boldsymbol{K}_{x}\right)^{-1} \boldsymbol{b}_{d} .
$$

Remark 5: Note that the disturbance compensation gain $K_{d}$ in (14) is a general case and suitable for both matching and mismatching cases. For the matching case, i.e., $\boldsymbol{b}_{u}=\lambda \boldsymbol{b}_{d}$, $\lambda \in R$, it can be obtained from (14) that the disturbance compensation gain reduces to $K_{d}=-1 / \lambda$, which is the same as the standard ESOBC law (6) in most previous literatures.

The configuration of the proposed generalized extended state observer based control is shown by Fig. 1 .

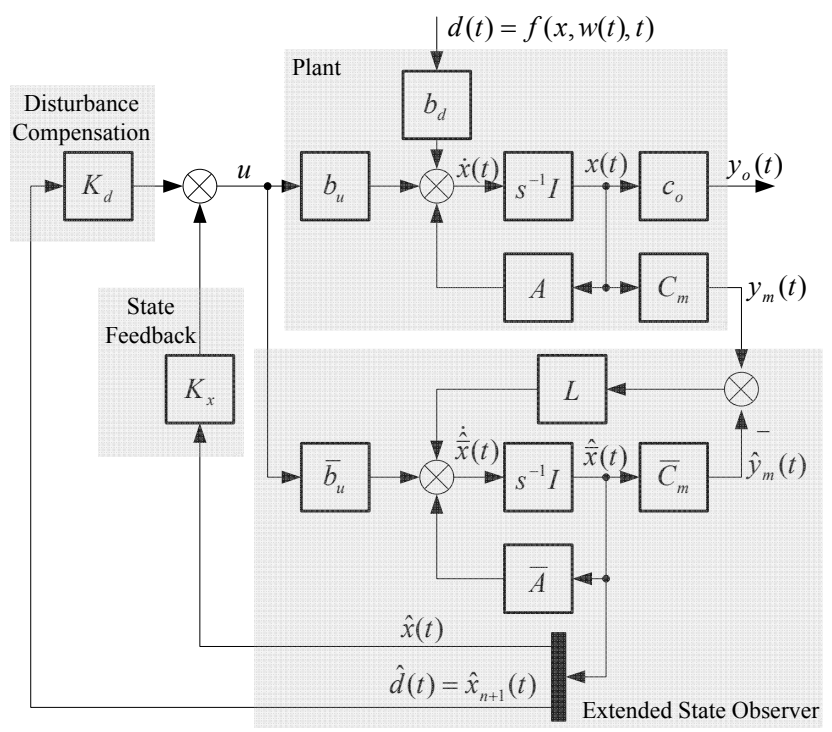

Fig. 1. Configuration of the proposed GESOBC method.

It will be shown next that the mismatched uncertainties can be eliminated from the output channel in steady state by the proposed control law.

\section{Stability and Disturbance Rejection Analysis}

Assumption 2: The lumped disturbances are bounded and have constant values in steady state, i.e., $\lim _{t \rightarrow \infty} \dot{d}(t)=$ $\lim _{t \rightarrow \infty} h(t)=0$ and $\lim _{t \rightarrow \infty} d(t)=D_{c}$.

The state and disturbance estimation errors are defined as

$$
\begin{gathered}
\boldsymbol{e}_{x}=\hat{\boldsymbol{x}}-\boldsymbol{x}, \\
e_{d}=\hat{d}-d,
\end{gathered}
$$

where $\hat{d}=\hat{x}_{n+1}$ represents the estimate of system uncertainties.

Combining Eqs. (10), (11), (15), with (16), the estimation error equation is given by

$$
\dot{e}=\boldsymbol{A}_{e} \boldsymbol{e}-\boldsymbol{E} h(t),
$$

where

$$
e=\left[\begin{array}{l}
\boldsymbol{e}_{x} \\
e_{d}
\end{array}\right], \boldsymbol{A}_{e}=\overline{\boldsymbol{A}}-\boldsymbol{L} \overline{\boldsymbol{C}}_{m}
$$

The bounded stability of the ESO can be obtained from the following conclusion.

Lemma 1 [38]: Assuming that the observer gain vector $\boldsymbol{L}$ in (11) is chosen such that $\boldsymbol{A}_{e}$ is a Hurwitz matrix, then the 
observer error, $\boldsymbol{e}$ for the ESO is bounded for any bounded $h(t)$.

Lemma 2: The following single-input linear system

$$
\dot{x}=A x+B u,
$$

is asymptotically stable if $A$ is a Hurwitz matrix, $u$ is bounded and satisfies $\lim _{t \rightarrow \infty} u(t)=0$. The proof can be found in Appendix B.

Lemma 3: For system (19), if matrix $A$ is Hurwitz and $\lim _{t \rightarrow \infty} u(t)=U_{c} \neq 0$, the state converges to a constant vector $-A^{-1} B U_{c}$, i.e., $\lim _{t \rightarrow \infty} x(t)=-A^{-1} B U_{c}$. The result can be easily followed from Lemma 2 by coordinate transformations.

1) In the Case of Known States: If the states are available, the composite control law is designed as (12). The stability and disturbance rejection performance is analyzed by the following theorems.

Theorem 1: Suppose that Assumption 1 is satisfied. The bounded stability of system (8) under the proposed GESOBC law (12) for any bounded $h(t)$ and $d(t)$ is guaranteed if the observer gain $\boldsymbol{L}$ in (11) and the feedback control gain $\boldsymbol{K}_{x}$ in (12) are selected such that $\boldsymbol{A}_{e}$ in (18) and $\boldsymbol{A}_{f}=\boldsymbol{A}+\boldsymbol{b}_{u} \boldsymbol{K}_{x}$ are Hurwitz matrices, respectively.

Proof: Combining system (8), composite control law (12), with error system (17), the closed-loop system in the presence of known states is given as

$$
\begin{aligned}
{\left[\begin{array}{c}
\dot{\boldsymbol{x}} \\
\dot{\boldsymbol{e}}
\end{array}\right]=} & {\left[\begin{array}{cc}
\boldsymbol{A}_{f} & \boldsymbol{b}_{u} \overline{\boldsymbol{K}} \\
\mathbf{0} & \boldsymbol{A}_{e}
\end{array}\right]\left[\begin{array}{c}
\boldsymbol{x} \\
\boldsymbol{e}
\end{array}\right] } \\
& +\left[\begin{array}{cc}
\mathbf{0} & \boldsymbol{b}_{d}+\boldsymbol{b}_{u} K_{d} \\
-\boldsymbol{E} & \mathbf{0}
\end{array}\right]\left[\begin{array}{c}
h \\
d
\end{array}\right],
\end{aligned}
$$

where $\overline{\boldsymbol{K}}=\left[\mathbf{0}_{1 \times n}, K_{d}\right]$.

Since both $\boldsymbol{A}_{f}$ and $\boldsymbol{A}_{e}$ are Hurwitz matrices, it is obtained that

$$
\left[\begin{array}{cc}
\boldsymbol{A}_{f} & \boldsymbol{b}_{u} \overline{\boldsymbol{K}} \\
\mathbf{0} & \boldsymbol{A}_{e}
\end{array}\right],
$$

is also Hurwitz matrix.

It can be concluded from Lemma 1 that the closed-loop system (26) is bounded-input-bounded-output (BIBO) stable for any bounded $h(t)$ and $d(t)$ if $\boldsymbol{K}$ and $\boldsymbol{L}$ are properly selected.

Theorem 2: Suppose that Assumptions 1 and 2 are satisfied, also the observer gain $\boldsymbol{L}$ and the feedback control gain $\boldsymbol{K}_{x}$ are chosen such that matrices $\boldsymbol{A}_{e}$ in (18), $\boldsymbol{A}_{f}$ Hurwitz, and $\boldsymbol{c}_{o} \boldsymbol{A}_{f}^{-1} \boldsymbol{b}_{u}$ invertible. For system (8) under the control law (12), the lumped disturbances can be attenuated from the output channel in steady state under the proposed GESOBC law (12).

Proof: Substituting control law (12) into system (8) and considering (16), the state is expressed as

$$
\boldsymbol{x}=\left(\boldsymbol{A}+\boldsymbol{b}_{u} \boldsymbol{K}_{x}\right)^{-1}\left[\dot{\boldsymbol{x}}-\boldsymbol{b}_{u} K_{d} e_{d}-\left(\boldsymbol{b}_{u} K_{d}+\boldsymbol{b}_{d}\right) d\right] .
$$

Combining (8), (14), with (21), gives

$$
y_{o}=\boldsymbol{c}_{o}\left(\boldsymbol{A}+\boldsymbol{b}_{u} \boldsymbol{K}_{x}\right)^{-1} \dot{\boldsymbol{x}}+\boldsymbol{c}_{o}\left(\boldsymbol{A}+\boldsymbol{b}_{u} \boldsymbol{K}_{x}\right)^{-1} \boldsymbol{b}_{d} e_{d} .
$$

It can be observed from (22) that the lumped disturbances are removed from the output channels. Under the given conditions, the following results are obtained from Lemmas 2 and
3

$$
\lim _{t \rightarrow \infty} \dot{\boldsymbol{x}}(t)=0, \lim _{t \rightarrow \infty} \boldsymbol{e}(t)=\mathbf{0} .
$$

Combining (22) with (23), yields

$$
\lim _{t \rightarrow \infty} y_{o}(t)=0 \text {. }
$$

2) In the Case of Unknown States: If the state variables are unmeasurable, the estimate of both the lumped disturbance and states can be used for control design. In this case, the composite control law is designed as (13). By denoting $\boldsymbol{K}=$ $\left[\boldsymbol{K}_{x}, K_{d}\right]$, a compact expression of the control law (13) can be obtained

$$
u=\boldsymbol{K} \hat{\overline{\boldsymbol{x}}} .
$$

Theorem 3: Suppose that Assumption 1 is satisfied. The bounded stability of system (8) under the proposed GESOBC law (13) for any bounded $h(t)$ and $d(t)$ is guaranteed if the observer gain $\boldsymbol{L}$ in (11) and the feedback control gain $\boldsymbol{K}_{x}$ in (13) are selected such that $\boldsymbol{A}_{e}$ and $\boldsymbol{A}_{f}$ are Hurwitz matrices, respectively.

Proof: Combining system (8), composite control law (13), with error system (17), the closed-loop system is written as

$$
\begin{aligned}
{\left[\begin{array}{c}
\dot{\boldsymbol{x}} \\
\dot{\boldsymbol{e}}
\end{array}\right]=} & {\left[\begin{array}{cc}
\boldsymbol{A}_{f} & \boldsymbol{b}_{u} \boldsymbol{K} \\
\mathbf{0} & \boldsymbol{A}_{e}
\end{array}\right]\left[\begin{array}{c}
\boldsymbol{x} \\
\boldsymbol{e}
\end{array}\right] } \\
& +\left[\begin{array}{cc}
\mathbf{0} & \boldsymbol{b}_{d}+\boldsymbol{b}_{u} K_{d} \\
-\boldsymbol{E} & \mathbf{0}
\end{array}\right]\left[\begin{array}{l}
h \\
d
\end{array}\right] .
\end{aligned}
$$

Since both $\boldsymbol{A}_{f}$ and $\boldsymbol{A}_{e}$ are Hurwitz matrices, it is easy to prove that matrix

$$
\left[\begin{array}{cc}
\boldsymbol{A}_{f} & \boldsymbol{b}_{u} \boldsymbol{K} \\
\mathbf{0} & \boldsymbol{A}_{e}
\end{array}\right]
$$

is also Hurwitz matrix. The proof is completed by using the result in Lemma 1.

Theorem 4: Suppose that Assumptions 1 and 2 are satisfied, also the observer gain $\boldsymbol{L}$ and the feedback control gain $\boldsymbol{K}_{x}$ are chosen such that matrices $\boldsymbol{A}_{e}$ in (18), $\boldsymbol{A}_{f}$ Hurwitz, and $\boldsymbol{c}_{o} \boldsymbol{A}_{f}^{-1} \boldsymbol{b}_{u}$ invertible. For system (8) under control law (13), the lumped disturbances can be attenuated from the output channel in steady state with the proposed GESOBC law (13).

Proof: Combining (8) with (13), gives

$$
\boldsymbol{x}=\left(\boldsymbol{A}+\boldsymbol{b}_{u} \boldsymbol{K}_{x}\right)^{-1}\left[\dot{\boldsymbol{x}}-\boldsymbol{b}_{u} \boldsymbol{K} \boldsymbol{e}-\left(\boldsymbol{b}_{u} K_{d}+\boldsymbol{b}_{d}\right) d\right] .
$$

Based on (8), (27) and (14), the output can be represented as

$$
y_{o}=\boldsymbol{c}_{o}\left(\boldsymbol{A}+\boldsymbol{b}_{u} \boldsymbol{K}_{x}\right)^{-1}\left(\dot{\boldsymbol{x}}-\boldsymbol{b}_{u} \boldsymbol{K}_{x} \boldsymbol{e}_{x}\right)+\boldsymbol{c}_{o}\left(\boldsymbol{A}+\boldsymbol{b}_{u} \boldsymbol{K}_{x}\right)^{-1} \boldsymbol{b}_{d} e_{d} .
$$

Considering (23), the same result as (24) can be obtained from (28).

\section{FURTHER Discussions}

\section{A. Extension to MIMO System}

For the purpose of comparison with the standard ESOBC, only a SISO system with uncertainties in single channel is considered in Section III. Actually, the proposed GESOBC method is able to extend to multi-input-multi-output (MIMO) system with almost no modification. Here the MIMO system 
may include multiple disturbances in different channels. A general MIMO system is described as

$$
\left\{\begin{array}{l}
\dot{\boldsymbol{x}}=\boldsymbol{A} \boldsymbol{x}+\boldsymbol{B}_{u} \boldsymbol{u}+\boldsymbol{B}_{d} \boldsymbol{f}(\boldsymbol{x}, \boldsymbol{\omega}(\boldsymbol{t}), t), \\
\boldsymbol{y}_{m}=\boldsymbol{C}_{m} \boldsymbol{x} \\
\boldsymbol{y}_{o}=\boldsymbol{C}_{o} \boldsymbol{x}
\end{array}\right.
$$

where $\boldsymbol{x} \in \boldsymbol{R}^{n}, \boldsymbol{u} \in \boldsymbol{R}^{m}, \boldsymbol{y}_{m} \in \boldsymbol{R}^{r}, \boldsymbol{y}_{o} \in \boldsymbol{R}^{p}$, and $\boldsymbol{f} \in \boldsymbol{R}^{q}$.

1) Solvability of the Disturbance Compensation Gain: The disturbance compensation gain in (14) is no longer available since $\boldsymbol{C}_{o}\left(\boldsymbol{A}+\boldsymbol{B}_{u} \boldsymbol{K}_{x}\right)^{-1} \boldsymbol{B}_{u}$ is possibly noninvertible or even not a square matrix. In this case, it can be verified that an alternative but more general condition

$$
\boldsymbol{C}_{o}\left(\boldsymbol{A}+\boldsymbol{B}_{u} \boldsymbol{K}_{x}\right)^{-1} \boldsymbol{B}_{u} \boldsymbol{K}_{d}=-\boldsymbol{C}_{o}\left(\boldsymbol{A}+\boldsymbol{B}_{u} \boldsymbol{K}_{x}\right)^{-1} \boldsymbol{B}_{d}
$$

must be satisfied to guarantee the feasibility of the proposed method.

The disturbance compensation gain $\boldsymbol{K}_{d}$ can be solved from (30) if the following condition holds

$$
\begin{aligned}
& \left.\operatorname{rank}\left(\boldsymbol{C}_{o}\left(\boldsymbol{A}+\boldsymbol{B}_{u} \boldsymbol{K}_{x}\right)^{-1} \boldsymbol{B}_{u}\right)\right)= \\
& \quad \operatorname{rank}\left(\left[\boldsymbol{C}_{o}\left(\boldsymbol{A}+\boldsymbol{B}_{u} \boldsymbol{K}_{x}\right)^{-1} \boldsymbol{B}_{u},-\boldsymbol{C}_{o}\left(\boldsymbol{A}+\boldsymbol{B}_{u} \boldsymbol{K}_{x}\right)^{-1} \boldsymbol{B}_{d}\right] .\right.
\end{aligned}
$$

2) Conditions in Assumption 1: Another factor that possibly influences the feasibility of the proposed GESOBC for MIMO systems is the condition in Assumption 1 may not be satisfied with the increased number of the lumped disturbances. Consider a system with multiple lumped disturbances, depicted by

$$
\left\{\begin{array}{l}
\dot{x}_{1}=x_{2}+f_{1}\left(x_{1}, x_{2}, \omega, t\right) \\
\dot{x}_{2}=-2 x_{1}-x_{2}+u+f_{2}\left(x_{1}, x_{2}, \omega, t\right), \\
y_{m}=x_{1}
\end{array}\right.
$$

It can be easily verified that $\left(\overline{\boldsymbol{A}}, \overline{\boldsymbol{C}}_{m}\right)$ is not observable for (32) and the proposed GESOBC is unavailable. However, it is also noticed that the problem becomes feasible as more output information is accessible, which is shown by the following example that similar with (32) but with more measurable outputs

$$
\left\{\begin{array}{l}
\dot{x}_{1}=x_{2}+f_{1}\left(x_{1}, x_{2}, \omega, t\right) \\
\dot{x}_{2}=-2 x_{1}-x_{2}+u+f_{2}\left(x_{1}, x_{2}, \omega, t\right), \\
y_{1 m}=x_{1} \\
y_{2 m}=x_{2}
\end{array}\right.
$$

It can be demonstrated that $\left(\overline{\boldsymbol{A}}, \overline{\boldsymbol{C}}_{m}\right)$ is observable for (33) now.

Generally speaking, besides the conditions in Assumption 1, condition (31) should be satisfied to guarantee feasibility of the GESOBC for MIMO system. If $\left(\overline{\boldsymbol{A}}, \overline{\boldsymbol{C}}_{m}\right)$ is not observable, one may make the problem feasible by seeking more output information.

\section{B. Parameter Design for GESOBC}

As for the proposed GESOBC method, there are mainly three parameters, including feedback control gain $\boldsymbol{K}_{x}$, observer gain $\boldsymbol{L}$, and disturbance compensation gain $K_{d}$, to be designed. A fixed way to determine $K_{d}$ has been given in (14).

The most important designing parameters are $\boldsymbol{K}_{x}$ and $\boldsymbol{L}$. As discussed in Theorems 1-4, the necessary conditions are $\boldsymbol{L}$ and
$\boldsymbol{K}_{x}$ should be designed to guarantee the stability of the closedloop system. However, these conditions are not sufficient. The reason lies in that the lumped disturbances would be a function of the states, which can only be estimated if the observer dynamics is faster than the closed-loop dynamics. The same argument for the state observer based control method is available.

It can be found from Section III that the poles of ESO and the closed-loop system are eigenvalues of matrix $\boldsymbol{A}_{e}=$ $\overline{\boldsymbol{A}}-\boldsymbol{L} \overline{\boldsymbol{C}}_{m}$ and $\boldsymbol{A}_{f}=\boldsymbol{A}+\boldsymbol{b}_{u} \boldsymbol{K}_{x}$, respectively. If $\left(\boldsymbol{A}, \boldsymbol{b}_{u}\right)$ is controllable and $\left(\bar{A}, \bar{C}_{m}\right)$ is observable, the poles of both the closed-loop system and ESO can be placed arbitrarily.

To make the observer dynamic quicker than that of the closed-loop system, poles of ESO should be placed much more far away from the origin than those of the closed-loop system.

\section{ApPliCATION EXAMPLE AND SIMULATIONS}

\section{A. A simple numerical example}

To demonstrate the efficiency of the proposed GESOBC scheme, a second-order uncertain nonlinear system with mismatching condition is considered

$$
\left\{\begin{array}{l}
\dot{x}_{1}=x_{2}+e^{x_{1}}+w \\
\dot{x}_{2}=-2 x_{1}-x_{2}+u \\
y=x_{1}
\end{array}\right.
$$

By denoting $\boldsymbol{A}=\left[\begin{array}{cc}0 & 1 \\ -2 & -1\end{array}\right], \boldsymbol{b}_{u}=\left[\begin{array}{l}0 \\ 1\end{array}\right], \boldsymbol{b}_{d}=\left[\begin{array}{l}1 \\ 0\end{array}\right]$, $\boldsymbol{C}_{m}=\boldsymbol{c}_{o}=\left[\begin{array}{ll}\mathbf{1} & 0\end{array}\right], f(\boldsymbol{x}, w(t), t)=e^{x_{1}}+w$, it can be observed that system (34) has the formulation of (8).

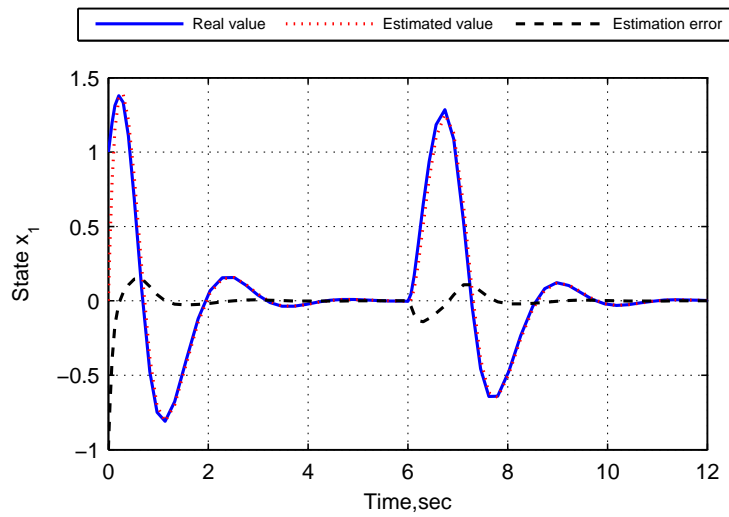

Fig. 2. Response curves of real and estimated values of state $x_{1}$.

To guarantee the convergence of ESO, the observer gain vector in (11) is chosen as $\boldsymbol{L}=\left[\begin{array}{lll}14 & -66 & 125\end{array}\right]^{T}$ such that the related ESO poles are $p_{\text {eso }}=\left[\begin{array}{lll}-5 & -5 & -5\end{array}\right]^{T}$. The feedback control gain in this example is designed as $\boldsymbol{K}_{x}=\left[\begin{array}{ll}-4 & -4\end{array}\right]$. The poles of the closed-loop system regardless of the uncertainties are $p_{c l}=\left[\begin{array}{ll}-2 & -3\end{array}\right]^{T}$ under such feedback control gain. The disturbance compensation gain can be calculated according to (14), giving as $K_{d}=-5$. Considering that the states are unmeasurable, the composite control law (13) is employed. The initial states of system (34) are $\boldsymbol{x}_{0}=\left[\begin{array}{ll}1 & 0\end{array}\right]^{T}$. The external disturbance $\omega=3$ acts on 


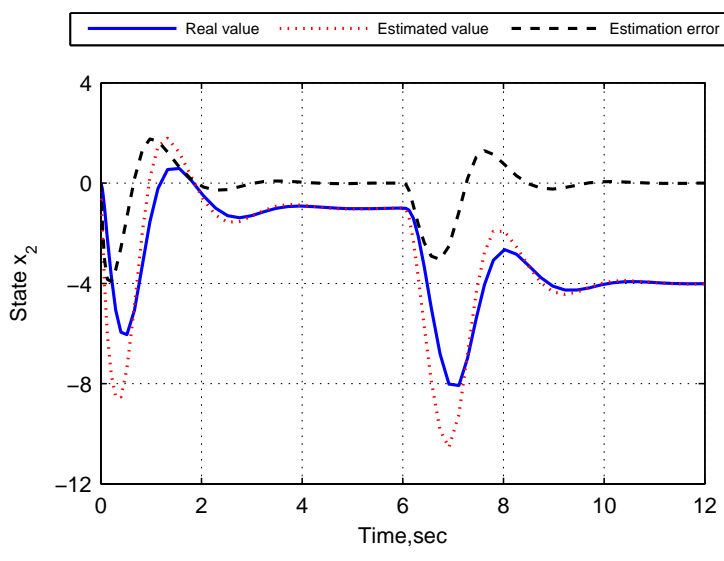

Fig. 3. Response curves of real and estimated values of state $x_{2}$.

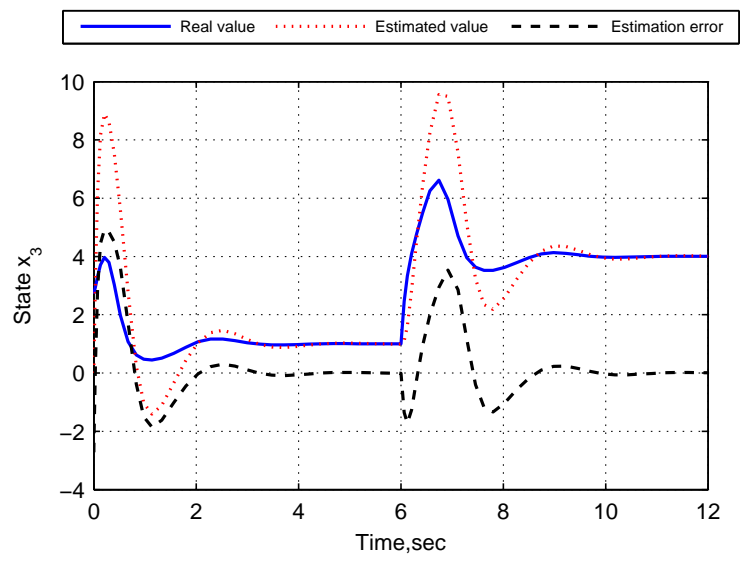

Fig. 4. Response curves of real and estimated disturbance $x_{3}=d$.

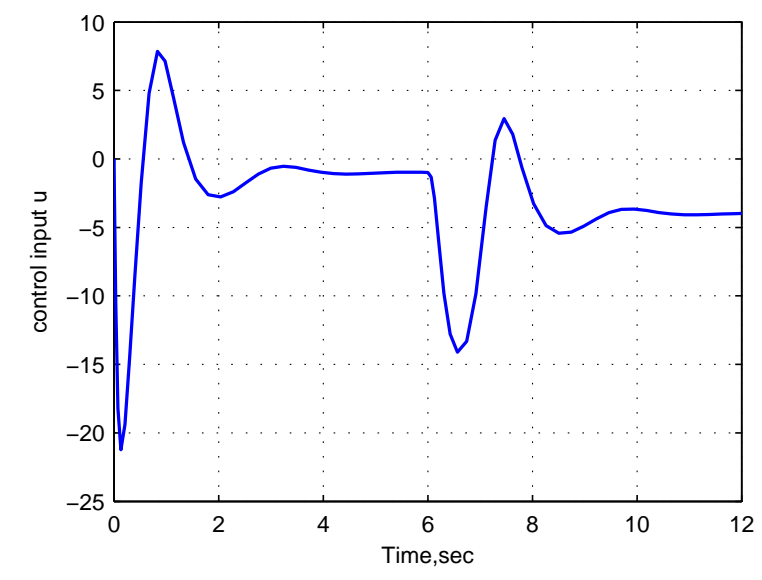

Fig. 5. Time history of the control input $u$. the system at $t=6 \mathrm{sec}$. The control objective is to remove the uncertainties from the output channel. Here the setpoint of the output is zero during the simulation. The response curves of the real, estimated states and their estimate errors are shown in the Figs. 2-4. The corresponding time history of the control input is shown in Fig. 5.

It can be observed from Fig. 2 that the output converges to the setpoint quickly in the presence of both uncertainties and external disturbances. As shown in Figs. 2-4, estimation errors of ESO converge to zero for all the states in such case of uncertainties.

\section{B. An application example}

Disturbance rejection of a MAGnetic LEViation (MAGLEV) system is studied in this part. The dynamic model of the MAGLEV system is given by [40].

1) Nonlinear Model: The complete nonlinear model for the MAGLEV suspension system is given by,

$$
\begin{gathered}
B=K_{b} \frac{I}{G}, \\
F=K_{f} B^{2}, \\
\frac{d I}{d t}=\frac{V_{\text {coil }}-I R_{c}+\frac{N_{c} A_{p} K_{b}}{G^{2}}\left(\frac{d z_{t}}{d t}-\frac{d Z}{d t}\right)}{\frac{N_{c} A_{p} K_{b}}{G}+L_{c}}, \\
\frac{d^{2} Z}{d^{2} t}=g-\frac{K_{f}}{M_{s}} \frac{I^{2}}{G^{2}}, \\
\frac{d G}{d t}=\frac{d z_{t}}{d t}-\frac{d Z}{d t},
\end{gathered}
$$

where variables $I, z_{t}, Z, \frac{d z_{t}}{d t}, \frac{d Z}{d t}, G, B$ and $F$ denote the current, the rail position, the electromagnet position, the rail vertical velocity, the electromagnet vertical velocity, the air gap, the flux density and the force, respectively. Signal $V_{\text {coil }}$ is the voltage of the coil. Other symbols in Eqs. (35)-(39) are system parameters listed in Table II.

TABLE II

PARAMETERS OF MAGLEV SUSPENSION SYSTEM

\begin{tabular}{|l|l|l|}
\hline Parameters & Meaning & Value \\
\hline$M_{s}$ & Carriage Mass & $1000 \mathrm{~kg}$ \\
$F_{o}$ & Nominal force & $9810 \mathrm{~N}$ \\
$G_{o}$ & Nominal air gap & $0.015 \mathrm{~m}$ \\
$R_{c}$ & Coil's Resistance & $10 \Omega$ \\
$B_{o}$ & Nominal flux density & $1 \mathrm{~T}$ \\
$L_{c}$ & Coil's Inductance & $0.1 \mathrm{H}$ \\
$I_{O}$ & Nominal current & $10 \mathrm{~A}$ \\
$N_{c}$ & Number of turns & 2000 \\
$V_{O}$ & Nominal voltage & $100 \mathrm{~V}$ \\
$A_{p}$ & Pole face area & $0.01 \mathrm{~m}^{2}$ \\
\hline
\end{tabular}

2) Linearized MAGLEV Suspension Model: The linearization of the MAGLEV suspension is based on small perturbations around the operating points. The following definitions are used in which the lower case letters define a small variation around the operating point and the subscript 'o' refers to the operating condition.

$$
\begin{aligned}
& B=B_{o}+b, \\
& F=F_{o}+f,
\end{aligned}
$$




$$
\begin{gathered}
I=I_{o}+i, \\
G=G_{o}+\left(z_{t}-z\right), \\
V_{c o i l}=V_{o}+u_{\text {coil }}, \\
Z=Z_{o}+z .
\end{gathered}
$$

The linearized state-space equation of the MAGLEV suspension model is expressed as

$$
\left\{\begin{array}{l}
\dot{\boldsymbol{x}}=\boldsymbol{A} \boldsymbol{x}+\boldsymbol{B}_{u} u+\boldsymbol{B}_{d} d \\
\boldsymbol{y}_{m}=\boldsymbol{C}_{m} \boldsymbol{x} \\
y_{o}=\boldsymbol{c}_{o} \boldsymbol{x}
\end{array}\right.
$$

where the states are the linearized current, vertical electro-

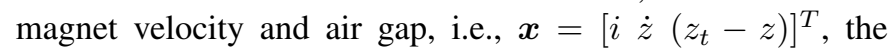
input $u=u_{\text {coil }}$ is the voltage, the track input $d=\dot{z}_{t}$ is the rail vertical velocity. Suppose that the measurable outputs are the air gap and the vertical velocity, i.e., $y_{m 1}=z_{t}-z$, $y_{m 2}=\dot{z}$. The controlled variable is the variation of air gap, i.e., $y=z_{t}-z$. The detailed linearization procedure can be found in [40], here the state matrix $\boldsymbol{A}$, the input matrix $\boldsymbol{B}_{u}$, the disturbance matrix $\boldsymbol{B}_{d}$, the output matrices $\boldsymbol{C}_{m}$ and $\boldsymbol{c}_{o}$ are given directly

$$
\begin{gathered}
\boldsymbol{A}=\left[\begin{array}{ccc}
\frac{-R_{c}}{L_{c}+K_{b} N_{c} \frac{A_{p}}{G_{o}}} & \frac{-K_{b} N_{c} A_{p} I_{o}}{G_{o}^{2}\left(L_{c}+K_{b} N_{c} \frac{A_{p}}{G_{o}}\right)} & 0 \\
-2 K_{f} \frac{I_{o}}{M_{s} G_{o}^{2}} & 0 & 2 K_{f} \frac{I_{o}^{2}}{M_{s} G_{o}^{3}} \\
0 & -1
\end{array}\right], \\
\boldsymbol{B}_{u}=\left[\begin{array}{c}
\frac{1}{L_{c}+K_{b} N_{c} \frac{A_{p}}{G_{o}}} \\
0 \\
0
\end{array}\right] \\
\boldsymbol{B}_{d}=\left[\begin{array}{c}
\frac{K_{b} N_{c} A_{p} I_{o}}{G_{o}^{2}\left(L_{c}+K_{b} N_{c} \frac{A_{p}}{G_{o}}\right)} \\
0 \\
1
\end{array}\right] \\
\boldsymbol{C}_{m}=\left[\begin{array}{ccc}
0 & 0 & 1 \\
0 & 1 & 0
\end{array}\right] \\
\boldsymbol{c}_{o}=\left[\begin{array}{lll}
0 & 0 & 1
\end{array}\right] .
\end{gathered}
$$

The major external disturbance in MAGLEV system is the deterministic inputs to the suspension in the vertical direction. Such deterministic inputs are the transitions onto the track gradients. The deterministic input components considered here are referred to [40] and shown in Fig. 6. They represent a gradient of $5 \%$ at a vehicle speed of $15 \mathrm{~m} / \mathrm{s}$ while the jerk level is $1 \mathrm{~m} / \mathrm{s}^{3}$.

It can be observed from Eqs. (46), (48) and (49) that the disturbances enter the system via different channel from that of the control input. In other words, the disturbances in the MAGLEV system are mismatching ones. The control specifications of the MAGLEV system under consideration of the deterministic track input are given in Table III [40].

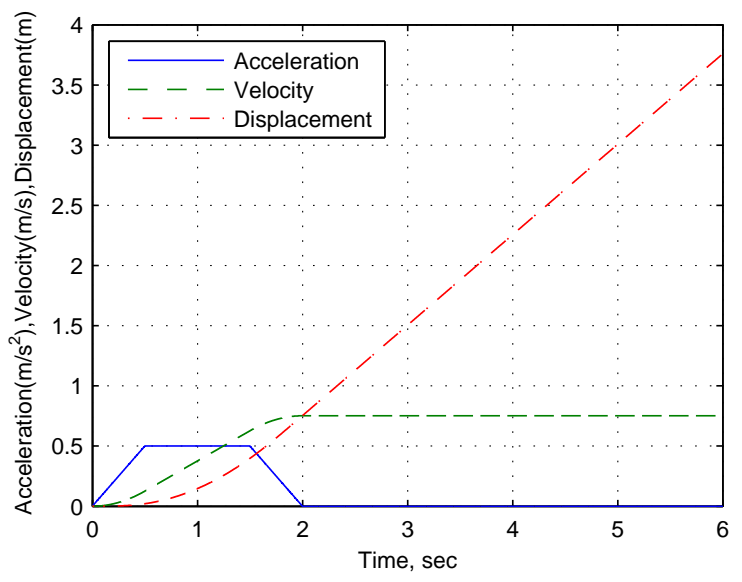

Fig. 6. Track input to the suspension with a vehicle speed of $15 \mathrm{~m} / \mathrm{s}$ and $5 \%$ gradient.

TABLE III

CONSTRAINTS FOR MAGLEV SUSPENSION SYSTEM

\begin{tabular}{|l||l|}
\hline Constraints & Value \\
\hline Maximum air gap deviation, $\left(\left(z_{t}-z\right)_{p}\right)$ & $\leq 0.0075 \mathrm{~m}$ \\
Maximum input coil voltage, $\left(\left(u_{c o i l}\right)_{p}\right)$ & $\leq 300 \mathrm{~V}\left(3 I_{o} R_{c}\right)$ \\
Settling time, $\left(t_{s}\right)$ & $\leq 3 \mathrm{~s}$ \\
Air gap steady state error, $\left(\left(z_{t}-z\right)_{e_{s s}}\right)$ & $=0$ \\
\hline
\end{tabular}

In the proposed GESOBC method, the observer gain is chosen as

$$
\boldsymbol{L}=\left[\begin{array}{cc}
79516 & -2370 \\
62.3 & 125.2 \\
130 & -1 \\
4000 & 0
\end{array}\right]
$$

The feedback control gain is designed as $\boldsymbol{K}_{x}=$ $\left[\begin{array}{lll}-60.6 & 591 & 40061\end{array}\right]$. The disturbance compensation gain can be calculated according to (14), giving as $K_{d}=-591.2$.

Response curves of both the output and input of the suspension system under the proposed GESOBC method are shown in Fig. 7. Response curves of the corresponding states are shown in Fig. 8. The disturbance and its estimate are shown in Fig. 9.

It can be observed from Fig. 7(a) that the maximum air gap deviation is less than $0.005 \mathrm{~m}$, the settling time is shorter than $2.4 \mathrm{~s}$ and there is no steady-state error. All of these performances satisfy the design requirements listed in Table III. As shown in Fig. 7(b), the maximum input voltage in such case is about $30 \mathrm{~V}$. Response curves in Fig. 8 show that both the current and the vertical electromagnet velocity vary smoothly and approach to the desired equilibrium points quickly. As shown in Fig. 9, the ESO can estimate the disturbance timely and accurately. The results demonstrate that the proposed GESOBC method has achieved satisfying performance in rejecting such practical disturbance.

\section{CONCLUSION}

The standard extended state observer based control (ESOBC) method is only available for a class of single-inputsingle-output (SISO) integral chain systems with disturbances/uncertainties satisfying the so called matching condi- 


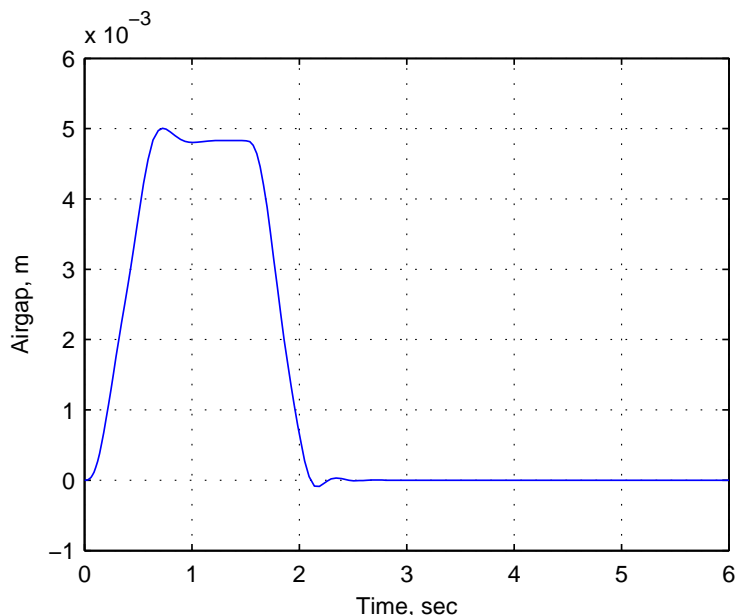

(a)

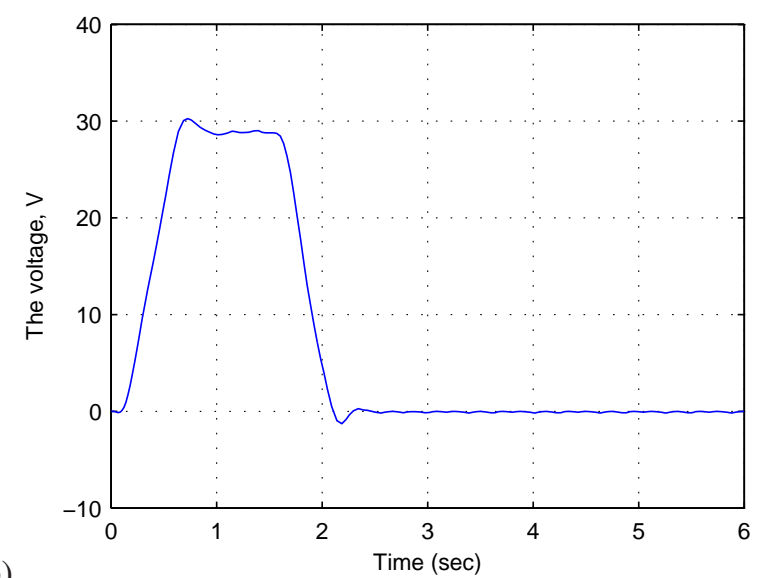

(b)

Fig. 7. Response curves of the input and output in the presence of deterministic track input: (a) the air gap, $z_{t}-z$, (b) voltage of the coil, $u_{\text {coil }}$.

tion. By appropriately developing a disturbance compensation gain, a generalized extended state observer based control (GESOBC) method has been proposed for general systems with mismatched uncertainties and non-integral-chain form. The proposed method can be extended to multi-input-multioutput (MIMO) systems with almost no modification. Both numerical and application examples have been designed and simulated to demonstrate the feasibility and efficiency of the proposed method.

\section{APPENDIX}

\section{A. Detailed Interpretation of Remark 3}

The observability matrices of $\left(\boldsymbol{A}, \boldsymbol{C}_{m}\right)$ and $\left(\overline{\boldsymbol{A}}, \overline{\boldsymbol{C}}_{m}\right)$ are

$$
\boldsymbol{P}_{o}=\left[\begin{array}{l}
\boldsymbol{C}_{m} \\
\boldsymbol{C}_{m} \boldsymbol{A} \\
\vdots \\
\boldsymbol{C}_{m} \boldsymbol{A}^{n-1}
\end{array}\right]
$$

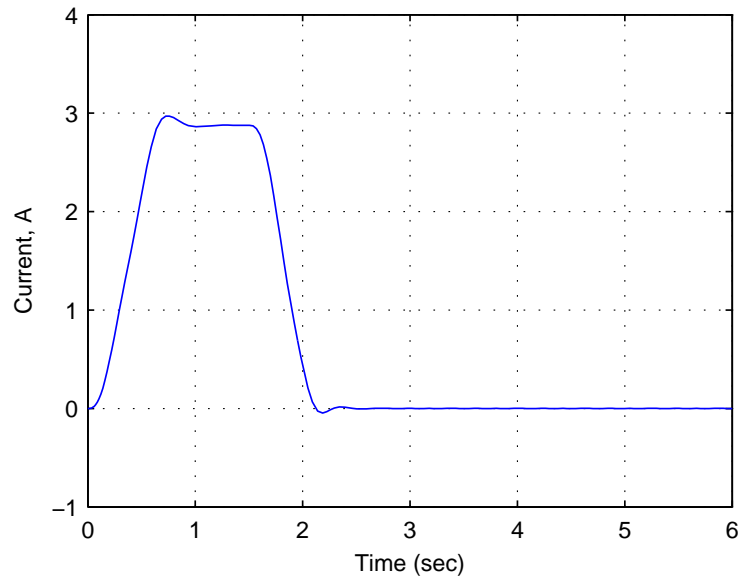

(a)

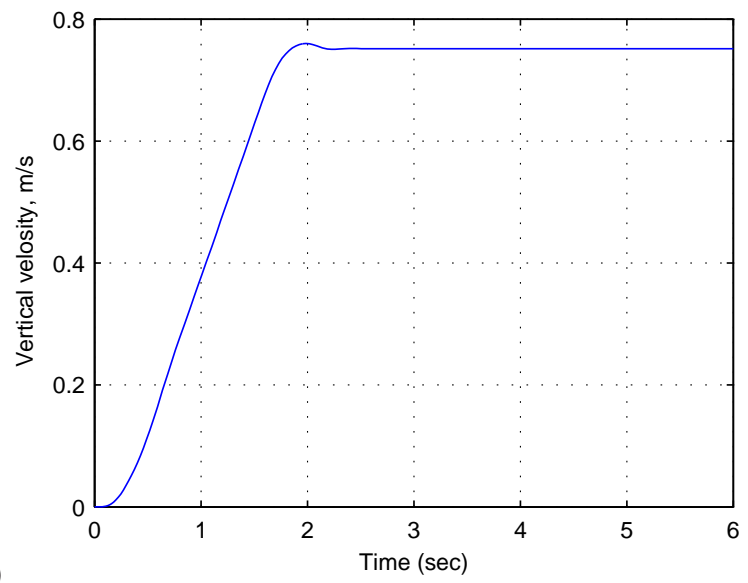

(b)

Fig. 8. Response curves of the states in the presence of deterministic track input: (a) the current, $i$, (b) the vertical electromagnet velocity, $\dot{z}$.

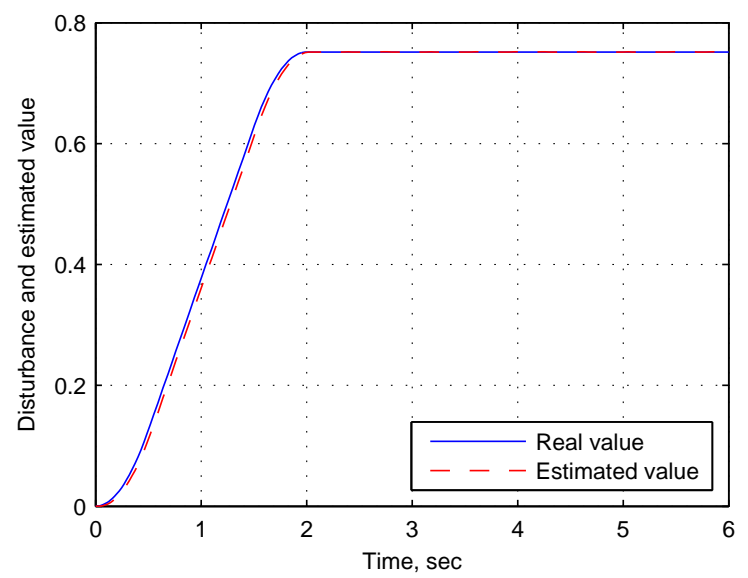

Fig. 9. Curves of the disturbance and its estimated value. 
and

$$
\overline{\boldsymbol{P}}_{o}=\left[\begin{array}{l|l}
\boldsymbol{C}_{m} & 0 \\
\boldsymbol{C}_{m} \boldsymbol{A} & \boldsymbol{C}_{m} \boldsymbol{b}_{d} \\
\boldsymbol{C}_{m} \boldsymbol{A}^{2} & \boldsymbol{C}_{m} \boldsymbol{A} \boldsymbol{b}_{d} \\
\vdots & \vdots \\
\boldsymbol{C}_{m} \boldsymbol{A}^{n-1} & \boldsymbol{C}_{m} \boldsymbol{A}^{n-2} \boldsymbol{b}_{d} \\
\hline \boldsymbol{C}_{m} \boldsymbol{A}^{n} & \boldsymbol{C}_{m} \boldsymbol{A}^{n-1} \boldsymbol{b}_{d}
\end{array}\right] .
$$

Assume that $\left(\boldsymbol{A}, \boldsymbol{C}_{m}\right)$ is not observable. Without loss of generality, $\boldsymbol{C}_{m} \boldsymbol{A}^{n-1}$ in matrix $\boldsymbol{P}_{o}$ can be expressed as

$$
\boldsymbol{C}_{m} \boldsymbol{A}^{n-1}=\lambda_{1} \boldsymbol{C}_{m}+\lambda_{2} \boldsymbol{C}_{m} \boldsymbol{A}+\cdots+\lambda_{n-1} \boldsymbol{C}_{m} \boldsymbol{A}^{n-2},
$$

where $\lambda_{i}(i=1, \cdots, n-1)$ are constant coefficients.

Combining (54) with (55), gives

$$
\begin{aligned}
{\left[\boldsymbol{C}_{m} \boldsymbol{A}^{n} \boldsymbol{C}_{m} \boldsymbol{A}^{n-1} \boldsymbol{b}_{d}\right] } & =\lambda_{1}\left[\boldsymbol{C}_{m} \boldsymbol{A} \boldsymbol{C}_{m} \boldsymbol{b}_{d}\right] \\
& +\lambda_{2}\left[\boldsymbol{C}_{m} \boldsymbol{A}^{2} \boldsymbol{C}_{m} \boldsymbol{A} \boldsymbol{b}_{d}\right]+\cdots \\
& +\lambda_{n-1}\left[\boldsymbol{C}_{m} \boldsymbol{A}^{n-1} \boldsymbol{C}_{m} \boldsymbol{A}^{n-2} \boldsymbol{b}_{d}\right] .
\end{aligned}
$$

From (54) and (56), it can be derived that $\operatorname{rank}\left(\overline{\boldsymbol{P}}_{o}\right)<n$.

\section{B. Proof of Lemma 2}

According to Final-value Theorem [39], if all poles of $s X(s)$ lie in the left half $s$ plane, $\lim _{t \rightarrow \infty} x(t)$ exists. Since $u(t)$ is bounded and satisfies $\lim _{t \rightarrow \infty} u(t) \stackrel{t \rightarrow \infty}{=}$, all poles of $s U(s)$ lie in the left half $s$ plane. In addition, all poles of $(s I-A)^{-1}$ also lie in the left half $s$ plane since $A$ is a Hurwitz matrix. To this end, all poles of $s X(s)$ lie in the left half $s$ plane. Thus, $\lim x(t)$ exists.

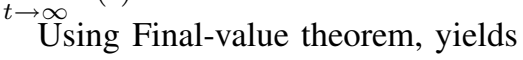

$$
\begin{aligned}
\lim _{t \rightarrow \infty} x(t) & =\lim _{s \rightarrow 0} s X(s) \\
& =\lim _{s \rightarrow 0} s(s I-A)^{-1} U(s) \\
& =\lim _{s \rightarrow 0}(s I-A)^{-1} \cdot \lim _{s \rightarrow 0} s U(s) \\
& =\lim _{s \rightarrow 0}(s I-A)^{-1} \cdot \lim _{t \rightarrow \infty} u(t) .
\end{aligned}
$$

Since $A$ is a Hurwitz matrix, $\lim _{s \rightarrow 0}(s I-A)^{-1}$ is bounded. Using the condition $\lim _{t \rightarrow \infty} u(t)=0$, it can be obtained from (57) that

$$
\lim _{t \rightarrow \infty} x(t)=0 .
$$

\section{REFERENCES}

[1] C. Johnson, "Accommodation of external disturbances in linear regulator and servomechanism problems," IEEE Trans. Autom. Control, vol. 16, no. 6, pp. 635-644, Dec. 1971

[2] K. Ohishi, M. Nakao, K. Ohnishi, and K. Miyachi, "Microprocessorcontrolled DC motor for load-insensive position servo system," IEEE Trans. Ind. Electron., vol. 34, no. 1, pp. 44-49, Feb. 1987.

[3] T. Umeno, and Y. Hori, "Robust speed control of DC servo motors using modern two degrees-of-freedom controller design," IEEE Trans. Ind. Electron., vol. 38, no. 5, pp. 363-368, Oct. 1991.

[4] W.-H. Chen, D. J. Ballance, P. J. Gawthrop, and J. O'Reilly, "A nonlinear disturbance observer for robotic manipulators," IEEE Trans. Ind. Electron., vol. 47, no. 4, pp. 932-938, Aug. 2000.

[5] W.-H. Chen, "Disturbance observer based control for nonlinear systems," IEEE-ASME Trans. Mechatron., vol. 9, no. 4, pp. 706-710, Dec. 2004.

[6] L. Guo, and W.-H. Chen, "Disturbance attenuation and rejection for systems with nonlinearity via DOBC approach," Int. J. Robust Nonlinear Control, vol. 15, no. 3, pp. 109-125, Feb. 2005.

[7] S. Kwon, and W.K. Chung, "Robust performance of a multiloop perturbation compensator," IEEE-ASME Trans. Mechatron., vol. 7, no. 2, pp. 190-200, Jun. 2002.
[8] S. Kwon, and W.K. Chung, "A discreate-time design and analysis of perturbation observer for motion control applications," IEEE Trans. Control Syst. Technol., vol. 11, no. 3, pp. 399-407, May. 2003.

[9] J.-H. She, M. Fang, Y. Ohyama, H. Hashimoto, and M. Wu, "Improving disturbance-rejection performance based on an equivalent-inputdisturbance approach," IEEE Trans. Ind. Electron., vol. 55, no. 1, pp. 380-389, Jan. 2008

[10] J.-H. She, X. Xin, and Y. Pan, "Equivalent-input-disturbance approachAnalysis and application to disturbance rejection in dual-stage feed drive control system," IEEE-ASME Trans. Mechatron., vol. 16, no. 2, pp. 330340, Apr. 2011

[11] J. Han, "Extended state observer for a class of uncertain plants," Control Decis., vol. 10, no. 1, pp. 85-88, 1995,(in Chinese).

[12] Z. Gao, Y. Huang, and J. Han, "An alternative paradigm for control system design," in Proc. 40th IEEE Conf. Decis. Control, 2001, vol. 5, pp. $4578-4585$.

[13] D. Sun, "Comments on active disturbance rejection control," IEEE Trans. Ind. Electron., vol. 54, no. 6, pp. 3428-3429, Dec. 2007.

[14] J. Han, "From PID to active disturbance rejection control," IEEE Trans. Ind. Electron., vol. 56, no. 3, pp. 900-906, Mar. 2009.

[15] Y. Xia, P. Shi, G. P. Liu, D. Rees, and J. Han, "Active disturbance rejection control for uncertain multivariable systems with time-delay," IET Contr. Theory Appl., vol. 1, no. 1, pp. 75-81, Jan. 2007.

[16] Q. Zheng, L. Q. Gao, and Z. Gao, "On stability analysis of active disturbance rejection control for nonlinear time-varying plants with unknown dynamics," in Proc. 46th IEEE Conf. Decis. Control, 2007, vol. 12-14, pp. 3501-3506.

[17] J. Su, H. Ma, W. Qiu, and Y. Xi, "Task-independent robotic uncalibrated hand-eye coordination based on the extended state observer," IEEE Trans. Syst. Man Cybern. Part B-Cybern., vol. 34, no. 4, pp. 1917-1922, Aug. 2004.

[18] J. Su, W. Qiu, H. Ma, and P.-Y. Woo, "Calibration-free robotic eyehand coordination based on an auto disturbance-rejection controller," IEEE Trans. Robot., vol. 20, no. 5, pp. 899-907, Oct. 2004.

[19] Y. X. Su, C. H. Zheng, and B. Y. Duan, "Automatic disturbance rejection controller for precise motion control of permanent-magnet synchronous motors," IEEE Trans. Ind. Electron., vol. 52, no. 3, pp. 814-823, Jun. 2005.

[20] S. H. Li, and Z. G. Liu, "Adaptive speed control for permanent-magnet synchronous motor system with variations of load inertia," IEEE Trans. Ind. Electron., vol. 56, no. 8, pp. 3050-3059, Aug. 2009.

[21] S. H. Li, H. X. Liu, and S. H. Ding, "A speed control for a PMSM using finite-time feedback control and disturbance compensation," Trans. Inst. Meas. Control, vol. 32, no. 2, pp. 170-187, April, 2010.

[22] G. Feng, Y.-F. Liu, and L. Huang, "A new robust algorithm to improve the dynamic performance on the speed control of induction motor drive," IEEE Trans. Power Electron., vol. 19, no. 6, pp. 1614-1627, Nov. 2004.

[23] Y. X. Su, C. H. Zheng, D. Sun, and B. Y. Duan, "A simple nonlinear velocity estimator for high-performance motion control," IEEE Trans. Ind. Electron., vol. 52, no. 4, pp. 1161-1169, Aug. 2005.

[24] D. Wu, and K. Chen, "Design and analysis of precision active disturbance rejection control for noncircular turning process," IEEE Trans. Ind. Electron., vol. 56, no. 7, pp. 2746-2753, Jul. 2009.

[25] Y. X. Su, B. Y. Duan, C. H. Zheng, Y. F. Zhang, G. D. Chen, and J. W. $\mathrm{Mi}$, "Disturbance-rejection high-precision motion control of a stewart platform," IEEE Trans. Control Syst. Technol., vol. 12, no. 3, pp. 364374, May. 2004.

[26] S. E. Talole, J. P. Kolhe, and S. B. Phadke, "Extended-state-observerbased control of flexible-joint system with experimental validation," IEEE Trans. Ind. Electron., vol. 57, no. 4, pp. 1411-1419, Apr. 2010.

[27] Y. Lu, K. W. E. Cheng, and S. L. Ho, "Auto-disturbance-rejection control for phase-shifted resonant converter," IEE Proc.-Electr. Power Appl., vol. 153, no. 5, pp. 711-718, Sep. 2006.

[28] B. Sun, and Z. Gao, "A DSP-based active disturbance rejection control design for a 1-kW H-bridge DC-DC power converter," IEEE Trans. Ind. Electron., vol. 52, no. 5, pp. 1271-1277, Oct. 2007.

[29] Q. Zheng, L. Dong, D. H. Lee, and Z. Gao, "Active disturbance rejection control for MEMS gyroscopes," IEEE Trans. Control Syst. Technol., vol. 17, no. 6, pp. 1432-1438, Nov. 2009.

[30] Y. Huang, K. Xu, J. Han, and J. Lam, "Flight control design using extended state observer and non-smooth feedback," in Proc. 40th IEEE Conf. Decis. Control, 2001, vol. 1, pp. 223-228.

[31] S. Li, X. Yang, and D. Yang, "Active disturbance rejection control for high pointing accuracy and rotation speed," Automatica, vol. 45, no. 8 , pp. 1854-1860, Aug. 2009. 
[32] Y. Xia, Z. Zhu, M. Fu, and S. Wang, "Attitude tracking of rigid spacecraft with bounded disturbances," IEEE Trans. Ind. Electron., available online, 2010.

[33] B. R. Barmish, and G. Leitmann, "On ultimate boundedness control of uncertain systems in the absence of matching condition," IEEE Trans. Autom. Control, vol. 27, no. 1, pp. 153-158, Feb. 1982.

[34] W.-H. Chen, "Nonlinear disturbance observer-enhanced dynamic inversion control of missiles," J. Guid. Control Dyn., vol. 26, no. 1, pp. 161-166, Jan.-Feb. 2003.

[35] Y. Abdel-Rady, and I. Mohamed, "Design and implementation of a robust current-control scheme for a PMSM vector drive with a simple adaptative disturbance observer," IEEE Trans. Ind. Electron., vol. 54, no. 4, pp. 1981-1988, Aug. 2007.

[36] K. Zhou, J. C. Doyle, and K. Glover, Robust and Optimal Control. London: Prentice Hall, 1996.

[37] W.-H. Chen, and L. Guo, "Analysis of disturbance oberver based control for nonlinear systems under disturbances with bounded variation," in Proceeding of Control 2004, UK, September 2004.

[38] Z. Gao, "Active disturbance rejection control: a paradigm shift in feedback control system design," in Proc. Amer. Control Conf., 2006, pp. 2399-2405.

[39] K. Ogata, Modern Control Engineering, 3rd ed. New Jersey: Prentice Hall, 1997.

[40] K. Michail, Optimised Configuration of Sensing Elements for Control and Fault Tolerance Applied to An Electro-Magnetic Suspension System, Ph.D. dissertation, Univ. Loughborough., Leics, England, Oct. 2009.

[41] W.-H. Chen, D. J. Ballance, P. J. Gawthrop, J. J. Gribble, and J. O'Reilly, "Nonlinear PID predictive controller," IEE Proc.-Control Theory Appl., vol. 146, no. 6, pp. 603-611, Nov. 1999.

[42] R. Errouissi, M. Ouhrouche, and W.-H. Chen, "Robust nonlinear generalized predictive control of a permanent magnet synchronous motor with an anti-windup compensator," in Proc. 2010 IEEE Int. Sympos. on Ind. Electron., 2010, pp. 3184-3189.

[43] A. Isidori, Nonlinear Control Systems: An Introduction, 3rd ed. New York: Springer-Verlag, 1995. 